\begin{tabular}{l}
$n$ \\
0 \\
3 \\
0 \\
0 \\
\hdashline \\
$\frac{1}{4}$
\end{tabular}

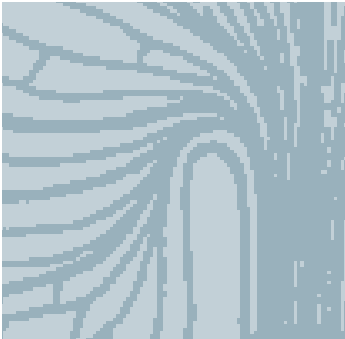

Servicios

\title{
Territoriales de Patrimonio Histórico
}

Luis Benitez de Lugo Enrich

Arqueólogo. Antropólogo
EI municipio es el ente público más básico de la organización territorial del Estado que cuenta con algunas competencias sobre Patrimonio Histórico. Aunque son notables aquellos casos en los que ciertos ayuntamientos se han planteado llevar a cabo -en necesaria colaboración con las Administraciones regional y estatal- una política sobre la materia y han creado los elementos necesarios para ello (arqueólogos municipales, Servicios Municipales de Patrimonio Histórico, etc.), no es menos cierto que esa es una realidad excepcional.

A través de un análisis de la legislación, primero, y con un serie de propuestas, después, este trabajo quiere crear una conciencia en los responsables políticos municipales y regionales acerca de la conveniencia de incentivar las actuaciones locales en el campo del Patrimonio Histórico o Cultural (entendidos ambos como sinónimos, y unificados en su denominación a partir de este punto simplemente como "Patrimonio").

\section{Ayuntamiento, patrimonio y legislación}

A la hora de plantear cualquier iniciativa local sobre patrimonio es necesario conocer el marco legal que afecta al territorio de dicha actuación.

Para aquellos municipios pertenecientes a comunidades autónomas que no hayan desarrollado una ley regional específica, la norma de aplicación es la de ámbito estatal: la Ley 16/85 de Patrimonio Histórico Español (en adelante LPHE). Este cuerpo jurídico tendrá sólo un carácter supletorio en aquellas autonomías que sí hayan desarrollado su propia legislación en la materia.

El tratamiento que han dado al municipio una parte de las leyes regionales obedece al mismo espíritu de la LPHE (en ocasiones son casi réplicas literales). Sólo las leyes más recientes suponen verdaderos avances cualitativos con respecto a la LPHE, contemplando explícitamente figuras innovadoras como la del arqueólogo municipal.

Algunas de las disposiciones que afectan a los ayuntamientos en las distintas legislaciones sobre Patrimonio son:

\section{Ley 16/85 de Patrimonio Histórico Español,} Artículo 7:

Los Ayuntamientos cooperarán con los organismos competentes para la ejecución de esta Ley en la conservación y custodia del Patrimonio Histórico Español comprendido en su término municipal, adoptando las medidas oportunas para evitar su deterioro, pérdida o destrucción. Notificarán a la Administración competente cualquier amenaza, daño o perturbación de la función social que tales bienes sufran, así como las dificultades y necesidades que tengan para el cuidado de estos bienes. Ejercerán, asimismo, las demás funciones que tengan expresamente atribuidas en virtud de esta Ley.

\section{Ley 4/1990 de Patrimonio Histórico de Castilla-La Mancha,} Artículo 4:

Los Ayuntamientos (...) cooperarán con la Junta de Comunidades de Castilla-La Mancha en la conservación y custodia del Patrimonio Histórico de Castilla-La Mancha comprendido en su ámbito territorial de actuación, adoptando las medidas oportunas para evitar su deterioro, pérdida o destrucción. Vendrán obligados a notificar a la Consejería de Educación y Cultura cualquier amenaza, daño o perturbación de la función social que tales bienes sufran, así como las dificultades y necesidades que tengan para el cuidado de estos bienes. Ejercerán, asimismo, las demás funciones que tengan atribuidas en función de esta Ley.

\section{Ley $7 / 1990$ de Patrimonio Cultural Vasco,}

\section{Artículo 4:}

I. Son instituciones competentes a efectos de la presente Ley:
a: El Gobierno Vasco.
b: Las Diputaciones Forales. c: Los Ayuntamientos.

2. En particular corresponde a los Ayuntamientos la misión de realzar y dar a conocer el valor cultural de los bienes integrantes del patrimonio histórico del pueblo vasco que radiquen en su término municipal. Les corresponde asimismo adoptar, en caso de urgencia, las medidas cautelares necesarias para salvaguardar los bienes del expresado patrimonio histórico cuyo interés se en- 
contrare amenazado. Todo ello sin perjuicio de las funciones que específicamente se les encomiende mediante esta Ley u otras disposiciones legales.

\section{Ley I//99 I de Patrimonio Histórico de Andalucía,} Artículo 4:

1. Corresponde a los Ayuntamientos la misión de realzar y dar a conocer el valor cultural de los bienes integrantes del Patrimonio Histórico Andaluz que radiquen en su término municipal.

Les corresponde asimismo adoptar, en caso de urgencia, las medidas cautelares necesarias para salvaguardar los bienes integrantes del patrimonio Histórico Andaluz cuyo interés se encontrare amenazado. Todo ello sin perjuicio de las funciones que específicamente se les encomiende mediante esta Ley o en virtud de la Ley I $6 / 85$ de Patrimonio Histórico Español.

\section{Ley 9/1993 de Patrimonio Cultural Catalán:}

\section{Artículo 3:}

I. En el ejercicio de sus competencias respectivas, la Administración de la Generalidad, los Consejos Comarcales y los Ayuntamientos velarán por la integridad del Patrimonio Cultural catalán, tanto público como privado, y por la protección, conservación, acrecentamiento, difusión y fomento de este patrimonio, estimulando la participación de la sociedad, por lo que se dotarán de medios materiales y personales adecuados.

3. Los Consejos Comarcales y los Ayuntamientos comunicarán inmediatamente a la Administración de la Generalidad cualquier situación de peligro en la que se encuentren los bienes integrantes del patrimonio cultural catalán.

\section{Artículo 6:}

I. Los municipios que tengan la consideración de histórico-artísticos, según lo que determina la legislación municipal y de régimen local de Cataluña, crearán un organismo de estudio y propuesta para la preservación, conservación, protección y vigilancia de su patrimonio cultural. Si se trata de un municipio de menos de mil habitantes, éste órgano será creado por el Consejo Comarcal, que asegurará en él una presencia significativa del municipio afectado.

2. Corresponde a la potestad de autoorganización local determinar la composición y el funcionamiento de los órganos a los que se refiere el apartado I, que contarán necesariamente con el apoyo de profesionales cualificados en el campo del patrimonio cultural, con las condiciones de formación y titulación que sean establecidas por reglamento.

3. Los órganos a los que se refiere el apartado I emitirán informe previamente a la adopción de acuerdos municipales que afecten a la aprobación o a la modificación del planeamiento urbanístico.

4. Los municipios histórico-artísticos elaborarán un Catálogo de Patrimonio Cultural Inmueble de su término, en el que se especificarán las medidas de protección de acuerdo con esta Ley y la Legislación urbanística.

5. Los municipios con un Patrimonio Arqueológico importante dispondrán de un arqueólogo municipal, cuya obligatoriedad y cuyas funciones generales se especificarán por reglamento. Corresponde a la facultad de autoorganización local nombrar dicho arqueólogo y determinar sus funciones específicas.
Así pues, es posible establecer diferencias cualitativas importantes en las facultades y deberes con que cuentan los distintos municipios, dependiendo de su localización en una u otra Comunidad Autónoma.

Mientras que la legislación castellano-manchega y la estatal se limitan a establecer que los ayuntamientos, en el territorio de su competencia, deben evitar unas acciones (de deterioro, pérdida o destrucción de bienes culturales) y notificar otras a la Administración competente (daños, amenazas o perturbación de la función social de los bienes culturales; y también las dificultades y necesidades que se encuentren en el cumplimiento de su labor), la vasca, la andaluza y, sobre todo, la catalana, van más allá.

En estos últimos casos -País Vasco, Andalucía y Cataluñalas actuaciones de los ayuntamientos no deben limitarse a evitar o notificar ciertos hechos. Además de notificar los daños, amenazas, etc. sufridos por los bienes culturales, han de adoptar las medidas cautelares necesarias para salvaguardarlos. También se exhorta por ley a los entes locales a realzar, dar a conocer y difundir su Patrimonio.

Ambos imperativos legales suponen un paso notable en la autonomía organizativa de los municipios, que deben idear iniciativas originales que posibiliten esos mandatos legales.

Cataluña, por su parte, da un trato especial a aquellos municipios que cuentan con bienes ar-

\section{Este trabajo quiere crear conciencia en los respon-} sables políticos municipales y regionales acerca de la conveniencia de incentivar las actuaciones locales en el campo del Patrimonio Histórico y Cultural

queológicos o histórico-

artísticos. En ambos casos la ley contempla la creación de instancias administrativas (un arqueólogo municipal, en el primer caso, y un organismo específico, en el segundo) cuya labor se deberá centrar en la gestión de esos bienes culturales. En este punto, llama la atención el olvido al que se relegan aquellos bienes patrimoniales que no son arqueológicos o histórico-artísticos, como, por ejemplo, los etnográficos. Por otra parte, la legislación catalana faculta explícitamente a los Ayuntamientos a la hora de dotar con suficientes recursos humanos y materiales las tareas de protección, conservación, acrecentamiento, difusión y fomento del Patrimonio. Este es un paso indiscutible en el tratamiento legal del Patrimonio.

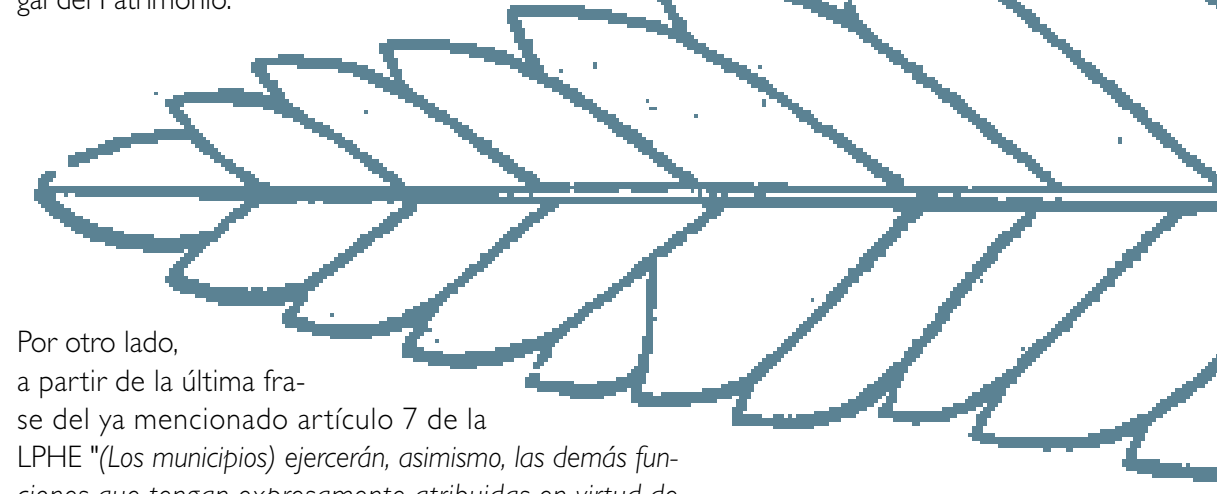
ciones que tengan expresamente atribuidas en virtud de esta Ley", puede entenderse la posible competencia del municipio en supuestos como el contemplado en el artículo 37 de esa ley: la expropiación forzosa. 
Hasta ahora se ha visto que hay casos en los que las competencias de los ayuntamientos se concretan más que en otros. Ello no significa que los marcos legales menos precisos impidan desarrollar políticas locales de Patrimonio. Simplemente, al ser más vagos, requieren un mayor esfuerzo imaginativo y una voluntad política más clara para llevar adelante proyectos.

\section{Arqueólogos territoriales}

Mientras que la figura de "arqueólogo provincial" se encuentra bastante -aunque, por desgracia, no completamente- extendida, la de arqueólogo municipal es menos habitual.

La no existencia hasta el momento de una definición clara, precisa y exhaustiva de lo que pueda ser un arqueólogo territorial conlleva una multiplicidad en la forma y funciones que adopta esta figura. Si bien cualquier profano sería capaz de explicar que un arqueólogo territorial es aquel profesional de la Arqueología que se ocupa de gestionar los trabajos arqueológicos dentro de un determinado territorio (municipio o provincia), ésta es una definición vaga y poco satisfactoria. Como se trata, a pesar de todo, de una definición bastante extendida, es nuestra intención realizar algunas precisiones.

Para empezar, la denominación de "arqueólogo territorial" deja fuera de su ámbito de actuación a otras parcelas relacionadas con el patrimonio no menos importantes que la Arqueología, tales como los archivos históricos, el Patrimonio arquitectónico, los bienes etnográficos, etc. Puede darse el extraño caso de que un municipio o provincia cuente con restos arqueológicos y no bienes culturales de otro tipo, pero no es lo habitual. Tampoco es frecuente que cuenten con un arqueólogo territorial, un antropólogo territorial, un archivero territorial y un paleontólogo territorial. Por el contrario, lo usual es que el arqueólogo territorial se ocupe de gestionar todos los asuntos relativos al Patrimonio Histórico de su zona. El conocimiento de la realidad pone de manifiesto que, ante lo limitado de los recursos públicos, es difícil encontrar una Administración regional o local que se plantee en serio la amplia dedicación a temas patrimoniales que supone la creación de puestos para técnicos en las diferentes áreas del Patrimonio. Parece razonable, pues, no limitar las pocas plazas laborales que se crean a una o dos materias, olvidando por completo las demás. El arqueólogo territorial que deje de lado, por poner un ejemplo, la catalogación del patrimonio arquitectónico de su municipio y su protección a través de las Normas Subsidiarias, por tratarse de una materia ajena a sus competencias, está haciendo un flaco servicio al Patrimonio.

Es cierto que la situación ideal supondría la existencia de un Servicio Territorial de Patrimonio que aglutinase a profesionales con distinta formación, tales como arqueólogos, antropólogos, historiadores del Arte, restauradores, conservadores, delineantes, paleontólogos, museólogos, pedagogos, etc. La adecuación a la realidad actual provoca que este utópico despliegue de medios se vea restringido a uno o dos técnicos en Patrimonio, que deben enfrentarse a un amplio elenco de asuntos.
La invitación que desde aquí lanzamos hacia la reconversión de la figura del arqueólogo municipal o provincial en un Técnico en Patrimonio no debe confundirse con una apología al intrusismo profesional. Es evidente que un etnógrafo puede no saber nada de restauración, y lo mismo un conservador de los métodos arqueológicos. Por ello, a la hora de contratar a estos técnicos, es preciso fijar unos criterios de selección exigentes y permitirles, una vez contratados, continuar con su formación, adecuándola a la realidad del municipio o provincia en cuestión. Además, la gestión de estos técnicos debería contar con la colaboración puntual de otros profesionales cuando fuese necesaria.

\section{Servicios Territoriales de Patrimonio}

Cuando el municipio o la provincia cuentan con un Patrimonio rico es conveniente gestionar sus recursos patrimoniales a través de una instancia administrativa, que podemos llamar Servicio de Patrimonio Histórico (en adelante SPH). El SPH aglutinaría personal de distinto tipo (administrativos, Técnicos en Patrimonio, etc.).

Dado que las circunstancias son en cada caso particulares, es difícil dibujar un perfil exacto de lo que debe ser la línea de trabajo a seguir por un SPH. No obstante, sí es posible establecer un mínimo de objetivos predefinidos que deberían ser considerados en todo proyecto de creación de un SPH.

\section{Los objetivos de un SPH deberían ser:}

a. Investigación: La primera labor del SPH consistiría en conocer el Patrimonio. Este es requisito sine qua non ha lugar plantearse otras acciones, tales como proteger y difundir. Evidentemente, para proteger primero hay que saber qué hay que proteger.

b. Protección: El Patrimonio sufre agresiones constantes de diversa índole. Identificar qué agresiones son las más graves, por qué motivo tienen lugar y plantear posibles soluciones para detenerlas constituye el segundo de los posibles objetivos del SPH.

c. Conservación: El paso del tiempo y la acción humana son dos de los factores que más alteran los restos patrimoniales. Por ser factores ineludibles, o difícilmente eludibles, es preciso intentar la minimización de sus consecuencias.

d. Difusión: Una labor prioritaria del SPH ha de ser la divulgación del Patrimonio. Con ello se facilitará el mayor aprecio de la población por el Patrimonio, circunstancia ésta básica para su protección y conservación.

e. Rentabilización social: Los restos patrimoniales, según distintos cuerpos legales, han llegado a ser patrimoniales exclusivamente por la función social que cumplen. Conseguir que el conjunto de la población tenga acceso a su comprensión y disfrute es el medio para dotar al Patrimonio de una verdadera dimensión social. 
f. Asesoramiento técnico: Se colaborará con otros organismos de la Administración y con entidades públicas y privadas en todo asunto que pueda afectar al $\mathrm{Pa}$ trimonio (Normas Subsidiarias, Planes Generales, proyectos urbanísticos y de obras públicas, etc.).

Para la consecución de estos objetivos básicos podrían desarrollarse, entre otras, las siguientes actuaciones:

\section{Objetivo a (Investigación):}

I. Inventario de recursos patrimoniales (carta arqueológica, catálogo de arquitectura popular, inventario de bienes culturales del Ayuntamiento, inventario de los fondos de los museos, ordenamiento de los archivos parroquiales y municipales, etc.).

\section{Objetivo b (Protección):}

I. Plan para la identificación y puesta en funcionamiento de los mecanismos que se muestren más eficaces en la protección del Patrimonio.

2. Formación de las Fuerzas de Seguridad locales y comarcales.

3. Sensibilización de la población.

\section{Objetivo c (Conservación):}

I. Diagnóstico sobre el estado de conservación de los bienes culturales. Intervenciones sobre aquellos que presenten mayores problemas.

2. Puesta en marcha de un Museo Municipal.

\section{Objetivo d (Difusión):}

I. Desarrollo del Departamento de Educación y Difusión del Museo Municipal y Provincial.

2. Difusión del Patrimonio a través de distintos medios (publicaciones, conferencias, cursos, reproducciones, etc.).

\section{Objetivo e (Rentabilidad Social):}

I. Fomento de un Turismo Cultural en la comarca. Creación de varios polos de atracción que favorezcan el desarrollo local y atraigan capitales externos.

2. Búsqueda y puesta en funcionamiento de todos aquellos cauces que incidan en el acercamiento de la población hacia su Patrimonio.
I. Intervención en la elaboración de los P.G.O.U., revisión de las NN.SS. o en todas aquellas actuaciones urbanísticas que pudieran suponer un peligro para la pervivencia del Patrimonio.

Este cúmulo de propuestas, a menudo interrelacionadas entre sí, es de mínimos. Es decir, éstas deberían ser las aspiraciones mínimas de todo SPH, sin que existiesen límites máximos para el desarrollo de cualquier iniciativa imaginativa tendente a la investigación, protección, conservación, difusión, fomento, etc. del Patrimonio.

Para llevar a cabo estas actividades -u otras similaresde una manera organizada y sistemática es precisa la existencia de uno o varios Técnicos en Patrimonio, a ser posible agrupados bajo la estructura administrativa que hemos llamado SPH.

Este tipo de organismos coinciden plenamente con el espíritu de todas las leyes citadas anteriormente y tienen cabida con la legislación actual

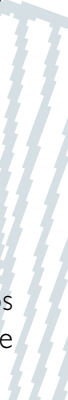

3
3
4
3

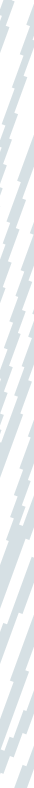

